\title{
Biografia do Orvalho: considerações sobre narrativa, vida e pesquisa em Educação Matemática
}

\author{
Dew's Biography: preamble about narrative, life and Mathematics \\ Education research
}

Filipe Santos Fernandes*

\begin{abstract}
Resumo
Neste texto, buscamos articular três temas: a narrativa, a vida e a pesquisa em Educação Matemática. Atravessados por uma discussão junto à poesia de Manoel de Barros e a diversos autores contemporâneos, destacamos, em termos filosóficos, metodológicos e históricos, os encantamentos e perigos da mobilização de narrativas de vida, em suas mais variadas formas, na pesquisa em ciências humanas. Ao final, pretendemos que as discussões apresentadas sejam um convite para novos modos de se praticar a pesquisa e, como que em uma reverberação, a pesquisa em Educação Matemática.
\end{abstract}

Palavras-chave: Biografia. Educação Matemática. Narrativa. Pesquisa.

\begin{abstract}
In this paper, we seek to bring together three themes: narratives, lives, and researches in Mathematics Education. Taking into consideration the poetry from Manoel de Barros and a wide variety of contemporary authors, we emphasize - in terms of philosophy, methodology, and history - the enchantments and dangers of using life narratives, in its various forms, for researches in human sciences. In the end, we expect that the presented discussions will be an invitation to new ways of practicing research and, like a reverberation, the research in Mathematics Education.
\end{abstract}

Keywords: Biography. Mathematics Education. Narrative. Research.

1 Introdução

A proposta deste artigo é articular três temas: a narrativa, a vida e a pesquisa em Educação Matemática. Evidentemente, uma proposta como essa poderia ser empreendida de

\footnotetext{
" Doutorando em Educação Matemática pela Universidade Estadual Paulista "Júlio de Mesquita Filho" (UNESP/Rio Claro). Endereço para correspondência: Rua 8B, 1137, Vila Indaiá, CEP 13506-739, Rio Claro, São Paulo, Brasil. E-mail: fernandes.fjf@gmail.com.
} 
várias formas, mas é optando por um caminho que perpassa a Literatura e a Filosofia que teceremos nossas considerações. Por um lado, a poesia de Manoel de Barros, em dois momentos, promoverá problematizações que se instauram no sutil limiar da narrativa e da vida. Por outro, a Filosofia da Diferença nos permitirá caminhos que articulam a narrativa, a vida e a pesquisa. De tudo isso, pensamos a Educação Matemática.

Seguindo pela Literatura, permitiremos a este texto alguns devaneios por uma escrita literária. Do mesmo modo, se propomos discutir a pesquisa em um viés filosófico, teremos momentos em que a escrita acadêmica prevalecerá. É claro que, já antecipamos, não haverá privilégios de uma escrita ou outra. A Literatura nos permitiu dizer o que, às vezes, não conseguíamos com a escrita científica, mas foi também insuficiente em certos momentos e, em alguns desses, a escrita de gabinete foi necessária. No entanto, em tantos outros momentos, nenhuma delas foi satisfatória: ainda há mais a dizer, mas não sabemos como. Há um silêncio aqui...

Assim, o texto trará dois movimentos. No primeiro, a Biografia do orvalho, de Manoel de Barros, nos suscita pensar a qualidade do bio de uma biografia, provocando-nos, no âmbito filosófico, uma discussão sobre os usos da narrativa de vida para além e aquém da constituição de sujeitos como compreendido na Modernidade. No segundo, ao convidar um fragmento de Livro sobre Nada, também de Manoel de Barros, provocamos uma discussão sobre como esses usos das narrativas de vida - biografias, autobiografias, relatos, depoimentos, diários, poemas e outras - desdobram-se em modos de se praticar a pesquisa e, como que em uma reverberação, a pesquisa em Educação Matemática.

\section{Biografia do orvalho}

Biografia do Orvalho

12 (Apêndice)

1. Ninguém consegue fugir do erro que veio.

2. Poema é lugar onde a gente pode afirmar que delírio é sensatez.

3. A limpeza de um verso pode estar ligada a um termo sujo.

4. Por não ser contaminada por contradições, a linguagem dos pássaros só produz gorjeios.

5. O início da voz tem formato de sol.

6. O dom de esculpir o orvalho só encontrei na aranha.

7. Pelos meus textos sou mais mudado que pelo meu existir.

8. Não é por fazimentos cerebrais que se chega ao milagre estético senão que por instinto linguístico.

9. Sabedoria pode ser que seja mais estudado em gente que em livros.

10. Quem se encosta em ser concha é que pode saber das origens do som. 
Os versos acima fazem parte da poesia Biografia do Orvalho, de Manoel de Barros (2010). Quando a descobrimos, a possível incoerência do título provocou uma inquietação sobre as impossibilidades de se biografar ${ }^{1}$ um orvalho. Isso porque sempre aprendemos que, etimologicamente, o termo bio faz referência à vida, assim como grafia refere-se à escrita - a biografia seria, pois, a escrita de uma vida. Ora, mas o orvalho não tem vida. Tem? Um cão, uma lesma, uma árvore têm; não o orvalho! É possível, então, biografar um cão, uma lesma, uma árvore? Que fazimentos nos levariam a biografar a lesma, o cão? O que constituiria uma biografia de uma árvore? (O movimentar das folhas com o passar do vento, o nascimento de folha nova em galho antigo, sua nova condição de casa para passarinho?).

Poderíamos pensar que não importa biografar um cão, uma lesma ou uma árvore. A contra resposta seria: não importa para quem? Imagino que um veterinário, um biólogo e um ecólogo prontamente se manifestariam. Mas, ao descrever estruturas, comportamentos e funcionamentos, estes profissionais fazem uma biografia? Pelos etimólogos, nos parece que sim. Mas biografar é somente isto, escrever uma vida? Biologicamente, vida é o estado entre o nascimento e a morte, mas já vi circular em livrarias e bibliotecas biografia de gente viva. $\mathrm{O}$ que se entende, afinal, pelo bio em biografia?

Voltemos para o orvalho. Desconhecemos cientista que diria que orvalho tem vida. Sua biografia poderia ser uma licença poética, um recurso de estilo para nos fazer vivenciar algo. (Isso sim, provavelmente, seria dito pelos cientistas da Linguagem). No entanto, mesmo assumindo isso, ficamos na posição de leitores desse algo do qual a Biografia do Orvalho quer nos fazer tocar.

Uma proposição: talvez não se trate de questionar se o orvalho tem ou não vida, mas sim de inventar as relações que constituem uma vida-orvalho, seus modos de ser orvalho e orvalhar. Seria o existir no tímido acontecimento, às vezes raro, entre a penumbra fria da noite e o alvorecer? A frágil condição de deslizar em folha/flor e, por qualquer perturbação, mudar de estado, deslocar, escorrer? A subversão de não se deixar dominar, de não se poder simular, inventar? (Nunca vimos orvalho de laboratório, tampouco alguém colhendo orvalho. Orvalho de plástico é tão artificial quanto a folha/flor que o sustenta). O interessante é que orvalho sem amanhecer é gota; sem pairar em folha/flor, gota; sem pratear a noite, gota... Orvalho não é

\footnotetext{
${ }^{1}$ Entende-se, aqui, a biografia como uma escrita de si, podendo a palavra ser substituída, neste texto, pelo diário, poema, autobiografia, memorial, história de vida ou qualquer "escrita que explora a configuração da própria linguagem e do próprio pensamento" (LARROSA, 2006, p. 17).
} 
orvalho sozinho: ele só é vida no conjunto de relações que estabelece. Orvalho não existe, o que existem são as circunstâncias que o constituem orvalho.

Vemos uma vida-orvalho como uma vida-pérola. Orvalho é o brilho da noite, pérola da mulher; orvalho acontece em momentos raros em alguns lugares, pérolas também; orvalho ornamenta, assim como pérola; ambos não são falseáveis e, em determinados lugares, ocorrem em tamanha abundância que nem especiais são. Vida-pérola é vida-orvalho, mas vida-pérola não é vida-orvalho. Pérola é protegida, orvalho nunca foi - orvalho, quando muito cercado, não é orvalho: é poça. Vida-orvalho pode estar vida-pérola. Sempre? Não! Pérola ornamenta corpos; orvalho de corpo é suor. Pérola não tem a leveza do orvalho. Orvalho não tem a rigidez de pérola. Aproximam-se e afastam-se.

A vida, como plano, é oferecedora de condições para um aprendizado. Ela, ao
mesmo tempo, é dupla: 'um sistema de estratificação particularmente complexo, e
um conjunto de consistência que conturba as ordens, as formas, as substâncias'. A
vida corte no caos é o real, a coexistência do atual e do virtual, é o grande meio,
propiciadora de tantos caminhos quantos forem traçados ou percorridos, imagináveis
ou inimagináveis; é o grande plano dos acontecimentos e dos devires. É prenhe de
possibilidades, fervilha de multiplicidades que saltitam e provocam danças. (ROOS,
2004, p. 3)

A vida é, pois, algo que não está em nós; e viver não é apenas um fazimento biológico, do nascimento à morte. Vida é o puro devir do real que não se constitui apenas nos estados de coisas (ser orvalho, ser pérola), mas em toda uma trama de relações que nos constituem, que nos tocam, que nos tornam; viver seria a potencialidade do acontecer na relação (viver orvalho, viver pérola). Nesse sentido, a vida está além e aquém das organizações orgânicas, de estruturas sociais, das estratificações políticas e econômicas: a vida é estabelecida nas relações, e viver é, potencialmente, devir (devir orvalho, devir pérola).

Biografar é narrar relações, e esse narrar é diferente de meramente descrever. A descrição pressupõe algo fixo, estratificado e constante, do qual admitimos, enquanto leitores, a capacidade de dizer sobre. A narrativa, por sua vez, não pressupõe a existência desse algo: o algo da narrativa se constitui no fazimento da narrativa. O narrar biográfico também é, pois, diferente da mera dissertação. Para dissertar é necessário defender algo já definido a partir de argumentos que o firmem, conduzindo esse algo à estratificação. Como o algo da biografia é a vida e como essa vida nunca é dada - por ser sempre transitória, conflituosa, não homogênea -, a biografia não será entendida como um relato descritivo ou dissertativo dela. Trata-se, aqui, da biografia como potência pela qual a invenção de uma vida pode advir. 
Mas também as relações que a biografia propõe narrar não são postas. Ser orvalho numa folha lisa é diferente de ser orvalho numa folha áspera. Não se trata apenas de pairar sobre a folha: é preciso estabelecer com ela uma relação a partir das forças que se dispõem. É preciso engendrar folha e orvalho. (Ou, constituir um orvalho-folha ou uma folha-orvalho). $\mathrm{O}$ orvalho só o é quando as relações convergem para uma forma-orvalho. Uma forma que não é dada a priori, nem mesmo estabelecida pela simples relação o orvalho deve estar sobre a folha; mas uma forma que seja, ela própria, múltipla.

Isso não se dá apenas em orvalho e pérolas, mas também em homens, em sua formahomem. Em um dado momento, nós, humanos, fomos engendrados por forças que constituíram nossa humanidade, nossa forma. Porém, assim como orvalho e pérola, o homem nem sempre é o mesmo. Em seu devir-humano, está tão submetido quanto o orvalho e a pérola às forças que lhe cabem. As forças se arranjam, geram relações e conduzem a uma forma; essa forma se dissolve, as relações perdem seu sentido e novos arranjos de força são estabelecidos. Muitas vezes, porém, uma determinada forma-homem se cristaliza e aquilo que era múltiplo torna-se unidade e, como se todos os homens fossem iguais, surge o imperativo da identidade. Mas um orvalho nunca é igual a outro ou a si mesmo, apesar de sua formaorvalho; uma pérola nunca é igual a outra ou a si mesma, apesar de sua forma-pérola. Assim também é o homem: apesar de sua forma, de um modo de ser homem, nenhum homem é igual ao outro, e nem mesmo igual a si.

Para fazer sentido uma biografia do orvalho é fundamental, pois, exigir um modo de pensar que não atribua ao homem - ou, a sua humanidade - uma identidade. É preciso ir além e aquém da forma-homem que, tomada pela ilusão da lógica do autoconhecimento, do autorreconhecimento e do autodescobrimento, vivencia as relações que ele próprio, sujeito, estabelece. É preciso operar justamente no avesso: são as relações que proporcionam a constituição de um modo de ser que, em sua racionalidade, se permite uma forma ou, como sugere Nietzsche (1999), “converte-se naquilo que se é” - um imperativo de compreender o humano em sua multiplicidade, em sua constante transformação.

Assim, instaura-se a necessidade de mudar o foco temporal da narrativa da vida ou, de outro modo, que o "converter-se naquilo que se é" não pressupõe uma finalidade, não possui uma origem ou método, e não é o revelar de algo que já está ali: venho a ser o que sou sendo o que sou... É necessário um mergulho na experiência, não no sentido de tempo que passa, mas no sentido de tempo que nos passa. Uma experiência que subverte a temporalidade linear e teleológica da vida, cuidando da existência e criando, em nós, um sentido ético-estético- 
político do viver, assumindo e decidindo sobre as incertezas, as variações e os conflitos que fazem parte do caminhar, do vir a ser do sujeito.

\begin{abstract}
E a experiência é o que nos passa e o modo como nos colocamos em jogo, nós mesmos, no que se passa conosco. A experiência é um passo, uma passagem. Contém o 'ex' do exterior, do exílio, do estranho, do êxtase. Contém também o 'per' de percurso, do 'passar através', da viagem, de uma viagem na qual o sujeito da experiência se prova e se ensaia a si mesmo. E não sem risco: no experiri está o periri, o periculum, o perigo. [...] E, no meio, um sujeito que já não se concebe mais como uma substância dada, mas como forma a compor, como uma permanente transformação de si, como o que está sempre por vir. (LARROSA, 2005, p. 66-67)
\end{abstract}

Ao nos atravessar, a experiência deixa marcas e são as marcas que escrevem (ROLNIK, 1993). Como disse Manoel de Barros (2010, p. 374-375), "Sei que meus desenhos verbais nada significam. Nada. Mas se o nada desaparecer a poesia acaba. Eu sei. Sobre o nada eu tenho profundidades". A questão: existe na superfície uma memória do visível, linear, hierarquizada, normatizada e contável para outro - um eu que conta para outro $e u$. Porém, na profundidade, no invisível, em nossa textura ontológica, vão "se fazendo [...] fluxos que constituem nossa composição atual, conectando-se com outros fluxos, somando-se e esboçando outras composições" (ROLNIK, 1993, p. 2); uma memória do invisível, que não é feita de fatos, de estados de coisas, mas de marcas.

Daí uma biografia - seja de orvalho, de pérola ou de homens - seria apenas uma composição narrativa, ou, ainda, uma composição de fazimentos narrativos que tomam a vida como obra de arte. (Uma obra de arte para aquele que a escreve, assim como o Agostinho de Agostinho, ou o Rousseau de Rousseau em suas respectivas Confissões). Não se trata de uma biografia que revela um sujeito, descrevendo o itinerário pessoal que o conduziu à sua formafinal. O converter-se naquilo que se é é um caminhar sem caminho em que o sujeito "não se pretende descrever ou um construir um caminho seguro para chegar à [sua] verdade [...]. O que se faz é, tão somente, descrever o caminho construído ao caminhar sem a pretensão de que ele se torne, para alguém, [...] caminho a ser percorrido" (CLARETO, 2007, p. 51-52).

Biografar é, então, operar num limiar entre a memória do visível e a memória do invisível, cabendo ao biógrafo promover uma simulação entre o real e o imaginário, entre o intempestivo e a estabilidade, entre o fluxo e a matéria. Simular é "a passagem do informe ao formado, do fluxo ao coagulado, do intensivo ao extensivo, do caos à ordem parcial, regional" (ALBUQUERQUE JR., 2007, p. 45), e o biógrafo, ao operar nessa linha, tem a tarefa de descolar uma memória cristalizada e devolvê-la ao fluxo do tempo, inventando vidas que não são antes dos conceitos, mas que são elas os próprios conceitos. (É preciso simular todo 
$\overline{\text { intempestivo do real para constituir uma vida-orvalho, uma vida-pérola. Quando o corte é }}$ feito no lugar que se convém, vida-orvalho pode ser vida-pérola. Mudando o corte, mesmo que acidentalmente, uma vida-orvalho pode deixar de ser uma vida-pérola. Trata-se do modo como se compõe, o que se deixa compor, o que se deseja compor).

As marcas competem ao fluxo assim como os fatos competem à matéria. Uma dada forma-homem atribuiu ao biógrafo a tarefa de descrever fatos, revelar o eu, definir uma identidade (única) talhada numa narrativa de temporalidade linear e teleológica. Acreditamos, no entanto, que a primeira tarefa do biógrafo seja justamente a de pressupor o oposto, afirmando positivamente o que operava no negativo da biografia: "a impossibilidade de cumprir a sua mais profunda tarefa: apresentar a verdade de uma vida reunida numa trama narrativa" (DUQUE-ESTRADA, 2009, p. 17). Uma impossibilidade ainda mais latente, "quando se tem o desejo de contar a verdade em um nível anterior aos simples critérios de veracidade da narrativa: aquele nível em que o próprio ideal de verdade já não basta pra dar conta das razões mais profundas do dizer" (DUQUE-ESTRADA, 2009, p. 17). Assim, o interesse do biógrafo deve se deslocar para a relação entre o fluxo e a matéria, comprometendo-se com o modo como os fatos se compõem na relação com as marcas que se dispõem, criando uma vida que é, naquela composição provisória, conceito. Interessam ao biógrafo, pois, as articulações narrativas da ideia de formação: "sua gênese, seus temas, sua estrutura, seus paradoxos, suas inversões, suas variações, suas derivações, suas metamorfoses, suas implicações filosóficas, pedagógicas, existenciais” (LARROSA, 2006, p. 184).

Não pretendendo empreender neste texto uma discussão sobre como se lembra e como se esquece, tomamos a memória como "um mistério que é a entrada no tempo" (LARROSA, 2006, p. 200). Essa memória não é aquilo que lembra fatos, objetos ou sujeitos, mas aquilo que os conhece, inventando-os. A biografia é, também e por isso, a entrada dessa memória na linguagem. No invisível, biografar é experienciar um eu fragmentado no tempo e, por recorrência, um $e u$ fragmentado na linguagem. Se a materialidade desse processo é a ilusão de um $e u$ identitário, livre e idealizado, trata-se de uma das facetas da humanidade de uma determinada forma-homem. Mas lá, onde opera a forma, também está o eu deformado, sem face ideal; um eu múltiplo, multifacetado e proliferante.

Essa ilusão biográfica está ligada à produção e à difusão dos escritos biográficos, que encontrou seu auge no século XVIII a partir da inserção das sociedades modernas europeias na cultura escrita; escoltada por intensas modificações nos modos de pensar, de agir e de 
saber construídos pela modernidade (GOMES, 2012), ou, diríamos, pela forma-homem constituída pela modernidade.

Segundo a leitura de Foucault (1999b), desde o medievo, com a difusão do Cristianismo, a confissão tornou-se um dos rituais mais importantes para constituição da verdade (tal como estabelecida pelo pensamento moderno). Talhada na possibilidade de configuração de um saber do sujeito, a confissão foi ganhando os mais amplos domínios e formas: pais e filhos, pedagogos e alunos, médicos e pacientes; interrogatórios, narrativas (auto)biográficas, consultas, relatórios; tudo transcrito, reunido e comentado. "De prazer de contar e ouvir [...]; passou-se a literatura ordenada em função da tarefa infinita de buscar, no fundo de si mesmo, entre as palavras, uma verdade que a própria forma da confissão acena como sendo inacessível” (FOUCAULT, 1999b, p. 59).

Nesse sentido, a confissão da verdade inscreveu-se no cerne da constituição dos sujeitos, entendidos nos dois sentidos da palavra - individualização (sujeito da razão) e sujeição (sujeito da moral). Tornou-se o procedimento mais eficaz do poder, tão profundamente incorporado a ponto de se tornar imperceptível como efeito que coage. Para isso, porém, foi necessária uma representação muito invertida, para "fazer acreditar que é de liberdade que nos falam todas essas vozes que há tanto tempo [...] ruminam a formidável injunção de dizer o que somos, o que fazemos, o que recordamos e o que foi esquecido, o que escondemos e o que se oculta, o que não pensamos e o que pensamos inadvertidamente" (FOUCAULT, 1999b, p. 60). O homem do Ocidente foi se configurando, aos poucos, como um animal confidente.

O sujeito - tanto o sujeito da razão como o sujeito da moral - é o grande invento no
qual o próprio sujeito assume a dupla tarefa de vigiar e de ser vigiado, de dominar e
de ser dominado, de julgar e de ser julgado, de castigar e de ser castigado, de mandar
e de obedecer. A crítica imanente e jurídica $[\ldots]$ faz instalar em nós o amo,
convertê-lo em parte de nós mesmos. Pelo simples expediente de converter-nos em
donos de nós mesmos, a crítica nos faz livres e escravos ao mesmo tempo: somos
livres por interiorização da lei. (LARROSA, 2005, p. 113)

O efeito desse procedimento de confissão foi, por sua vez, a constituição de uma verdade do e sobre o sujeito. Uma verdade que não está completa a partir daquele que fala, mas que se forma numa dupla tarefa, completando-se somente naquele que a recolhe. Assim, compete ao que escuta uma função hermenêutica: "Seu poder em relação à confissão não consiste somente em exigi-la, antes dela ser feita, ou em decidir após ter sido proferida, porém constituir, através dela e de sua decifração, um discurso de verdade" (FOUCAULT, 1999b, p. 66). Aqui, segundo Michel Foucault, coloca-se o grande perigo da confissão: se ela permite a 
constituição de um saber sobre aquilo que cinde no sujeito, sobre aquilo que o determina e o faz, ela pode ser usada como um violento dispositivo de subjetivação, modelando formas de ser, de agir e de pensar - ou, em outros termos, constituindo, efetivamente, uma formahomem.

Vemos uma ampla disseminação dos procedimentos de confissão ou, ainda, uma localização múltipla de sua coerção, extensão e domínio. No tocante à biografia, "Tudo se passa como se ele [o homem confessional do Ocidente] tenha atrás de si uma longa aprendizagem de autogoverno, materializada numa capacidade de se identificar com as narrativas [...] que se dispõem em seu redor" (RAMOS DO Ó, 2010, p. 45).

Junto a Deleuze e Guattari (1995), pensamos que essa oposição não se dará por meio da distinção entre um eu e vários 'eus'. A multiplicidade pode convergir para um mesmo estado de coisas, uma forma. A biografia, portanto, não é um enunciado individual: ela é fruto de um agenciamento coletivo, uma multiplicidade de um sujeito que se fragmenta e se constitui como narrativa; ela é uma de tantas outras formas que podem advir do sujeito, um modo de tecer considerações de uma vida narrativamente, uma composição dos fluxos que ocorrem no invisível.

Todo enunciado é o produto de um agenciamento maquínico, quer dizer, de agentes coletivos de enunciação [...]. Ora, o nome próprio não designa um indivíduo: ao contrário, quando o indivíduo se abre às multiplicidades que o atravessam de lado a lado, ao fim do mais severo exercício de despersonalização, é que ele admite seu verdadeiro nome próprio. O nome próprio é a apreensão instantânea de uma multiplicidade. $\mathrm{O}$ nome próprio é o sujeito de um puro infinito compreendido como tal num campo de intensidade. (DELEUZE; GUATTARI, 1995, p. 51)

Nessa diretriz, o gênero biográfico sugere um constante estranhamento que devemos estabelecer de nossa humanidade, de um eu que já não o é e que, ao mesmo tempo, entranha um eu que virá a ser. Isso implica o compromisso ético-estético-político de assumir a vida em suas virtualidades, em seus fluxos, em suas dissociações e descontinuidades, instaurando uma nova temporalidade - não mais um olhar sobre o passado como exemplaridade ou representação, mas um debruçar-se sobre a relação passado-presente buscando nela intervir. No movimento, parece caber ao biógrafo a tarefa de arbitrar o conflito entre as forças do passado e do futuro e, nesse sentido, abrir a possibilidade de produção de conhecimento. 


\title{
3 Sabiás e professores de Matemática: ressonâncias da narrativa de vida na pesquisa em
}

\section{Educação Matemática}

Em Livro sobre nada, Manoel de Barros (2010, p. 350) alerta:

\author{
A ciência pode classificar e nomear os órgãos de um sabiá \\ mas não pode medir seus encantos. \\ A ciência não pode calcular quantos cavalos de força existem \\ no canto de um sabiá. \\ Quem acumula muita informação, perde o condão de adivinhar: divinare. \\ Os sabiás divinam.
}

Sabiás e professores de Matemática. Nas ciências humanas, das mais gerais às mais específicas, tem perdurado uma crença - muitas vezes, velada - de que é possível, tomadas práticas e discursos, movimentos de identificação de pares, de aproximação de semelhantes, de igualação de outros. Nessas, sabiás são identificados pelos seus sons, aproximados pela qualidade de sua penugem, igualados pelo funcionamento de seus corpos... Porém, de que outros modos poderíamos biografar um sabiá, sensível a seus cantos e encantos?

No campo da Educação Matemática, a mobilização de narrativas de professores de Matemática - seja na forma de biografias, autobiografias, relatos, depoimentos, diários, poemas e tantas outras - tem produzido um conhecimento que, em muitos aspectos, não se diferencia dos movimentos acima. Muitas vezes, essas investigações têm sustentado a ideia de que é possível, por meio de uma leitura cuidadosa dessas narrativas, a determinação de quem é o professor de Matemática, de como atua esse professor, da Matemática por ele ensinada, das práticas pedagógicas que adota nessa ou naquela condição de trabalho. Subjaz, então, uma perspectiva de que a singularidade da narrativa, um micro, carrega a identidade de um grupo profissional e de suas práticas, o macro, permitindo um deslocamento do singular ao plural, da parcialidade à totalidade. Nesse tipo de abordagem, impera um poder epistemológico que, por meio da vigília cuidadosa e do registro detalhado dos comportamentos, constitui um saber sobre aquilo que cinde no sujeito.

Evidentemente, esse tipo de investigação tem trazido grandes contribuições ao nosso campo de pesquisa, porém, ao negligenciar a ideia de que pode haver algo de estranho na singularidade que escapa a qualquer movimento de totalização, tantas outras discussões não são empreendidas e, com elas, tantos outros modos de se pesquisar em Educação Matemática são suprimidos. Nesses novos modos de fazer pesquisa, o singular não é o oposto do plural, nem mesmo uma parcialização de um todo: trata-se de uma produção de conhecimento que 
não se refere à busca de fatos reveladores de uma identidade, mas de um traço, sempre provisório, das forças que na vida se estabelecem.

Notemos que o que está em jogo nessa discussão são as formas como a narrativa é pensada, em termos filosóficos, metodológicos e históricos, no âmbito do pesquisar. Aqui, insinuamos uma aproximação da narrativa com a pesquisa em Educação Matemática de um modo em que haja a contemplação da descontinuidade, do inusitado, do estranho, do marginal. Conferir ao gênero biográfico a possibilidade de conhecer implica a necessidade de assumir as fronteiras de uma linha de simulação, garantindo certa estabilidade em que significados possam ser produzidos. Essa estabilidade, no entanto, não é devida a uma ordem imperativa e valorativa, mas fundamentada em uma desordem que, negando a ordenação única, revele uma finidade de ordens possíveis ${ }^{2}$.

Essa perspectiva, quando assumida, tem desdobramentos importantes nas práticas de pesquisa que mobilizam histórias de vidas de professores de Matemática. Historicamente, o gênero biográfico foi amplamente utilizado nas décadas de 1920 e 1930, pela Escola de Chicago. Apesar de seu quase desaparecimento nas décadas seguintes, o gênero é retomado na década de 1980, passando a exigir uma reformulação dos fundamentos teórico-metodológicos que subsidiavam as pesquisas que o adotavam como abordagem metodológica. É nesse sentido que as pesquisas educacionais do período conferiam (e, muitas delas, ainda conferem) ao gênero a possibilidade de investigação da formação docente, com ênfase na vida do professor, suas carreiras e percursos, dispondo-se à compreensão da identidade de um grupo profissional - uma herança das incursões da Sociologia na Educação.

Acontece que nessas pesquisas, de um modo geral, as narrativas de vida são tomadas como uma espécie de experimento pelo qual é possível traçar considerações científicas em Educação Matemática. Tratam-se de narrativas de experiências, estratificadas, que possibilitam aos pesquisadores postular verdades, mesmo que ditas provisórias e carregadas da subjetividade do pesquisador. Nelas, as histórias de vidas de professores, obtidas por meio da oralidade ou da escritura, têm figurado apenas como um instrumento metodológico que, analisado segundo discursos previamente estabelecidos, constituem cenários monolíticos do passado e do presente. As narrativas compõem, assim, uma homilia na qual as vozes de professores acostam-se em uma fundamentação que as sustenta, sendo um fruto inevitável de

\footnotetext{
${ }^{2}$ Uma imagem interessante para essa discussão é empreendida em Foucault (1999a), no prefácio de As palavras e as coisas, junto à famosa "Enciclopédia Chinesa" de Borges.
} 
uma brada voz, identitária, que busca dizer quem é e o que faz o professor de Matemática. É preciso, por vezes, contornar esse perigo.

Se, de outro modo, exploramos a experiência da narrativa, aquilo que a singulariza, abrimos um espaço para outras pesquisas, possibilitando a constituição de cenários que não põem de parte a sensibilidade do pesquisador em relação ao modo como a narrativa o atravessa, mas de cenários que operam justamente nessa relação. De tal modo, interessam-nos as práticas de pesquisa em que as narrativas de professores articulam-se com as questões, buscando aproximações, distanciamentos, reformulações, questionamentos, discordâncias, subversões. Interessam-nos como as vidas desses professores problematizam as histórias contadas, o dito hegemônico, as formas estabelecidas. Interessam-nos os modos como as narrativas dobram os processos metodológicos, como distorcem as cartilhas antiquadas, como exigem novos procedimentos, regulações e cuidados. Interessam-nos, pois, as práticas de pesquisa em Educação Matemática que revelam a fragilidade do homem como texto a ser lido...

Ao propor isso, cremos, estamos abrindo um espaço para pensar a pesquisa ao lado da narrativa, isto é, um espaço em que a pesquisa carregue a imprevisibilidade da vida e de seus modos de narrá-la. Tal como uma narrativa, a pesquisa seria, pois, um espaço de enredos, de personagens e de narradores; um emaranhado de sujeitos, espaços e tempos que, em um movimento de composição e recomposição, permitem-se histórias. Um fazimento narrativo que, ao aproximar-se da Literatura, não se preocupa em determinar o que passou, mas o que está se passando; que não pretende dizer como as coisas aconteceram, mas que cria um campo do qual a invenção do que aconteceu possa advir. Um fazimento em que se narra sem julgamentos, hipóteses ou teses, mas comprometido eticamente em assumir o que aquela narração traz de novo, afirmando positivamente as potencialidades e os entraves: o que escapou às matérias e às formas de expressão utilizadas, o que outros narradores dotarão de outros significados, de outros sentidos, ou seja, aquilo que ainda não foi dobrado por seus modos de narrar. Um temor que, na perspectiva de conhecimento de Nietzsche (1999), mistura reverência e repulsa; que mistura riso, ódio e lamento. Um movimento em que as narrativas de vidas dos professores, ao nos atravessar, constituem a nossa história.

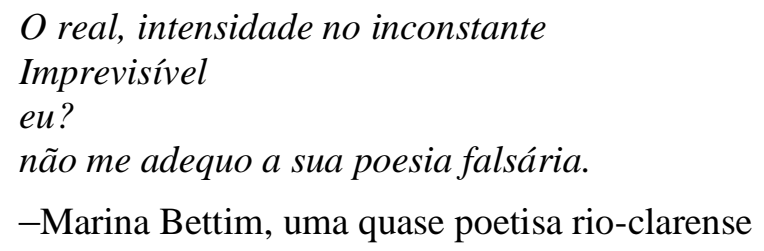

-Marina Bettim, uma quase poetisa rio-clarense 


\section{Considerações finais}

Explorar as potencialidades dessa discussão na prática de pesquisa em Educação Matemática não é uma tarefa fácil, tampouco redutível aos esforços empreendidos neste texto. De tal modo, qualquer esboço de compreensão sobre como a biografia pode apontar novos horizontes para as pesquisas em Educação Matemática já se instituiria como fracassado se seu objetivo fosse o da completude.

De alguma forma, as discussões aqui empreendidas tocam de modo claro as pesquisas que desenvolvemos nas mais diversas frentes. Na formação de professores, aceitar esta proposta significa compreender que, para além das formulações de classes, há sempre algo que distingue um dado professor daquilo que convencionamos chamar de professores de Matemática; há sempre algo que faz dele um ser estranho em relação aos demais. Na história da Educação Matemática, a proposta reverbera evitando a formulação de cenários monolíticos do passado, colocando em jogo os traços temporais e a previsibilidade do nosso e de outros tempos. Nas investigações sobre ensino-aprendizagem, a proposta convida para pensar os modos de tecer compreensões junto a narrativas de aulas de Matemática... Em uma frente ou outra, várias possibilidades se abrem.

Por fim, o que pode parecer uma fuga - a impossibilidade em dizer como fazer - é, na verdade, apenas um convite: que educadores matemáticos sensibilizem-se nessa direção e que, mediante esforços conjuntos, aproximem-se de novos modos de pensar as narrativas de vida na pesquisa em Educação Matemática.

\section{Agradecimento}

Agradeço aos membros do Grupo de Pesquisa História Oral em Educação Matemática $(\mathrm{GHOEM})^{3}$ pelas revisões e contribuições dadas após a leitura cuidadosa de parte deste texto. A Biografia do Orvalho poderia ser resumida como as inquietações de um pesquisador

\footnotetext{
${ }^{3}$ O GHOEM é um grupo de pesquisa interinstitucional cadastrado no CNPq e formado em 2002. De um modo geral, o interesse do grupo centra-se no estudo da cultura escolar e o papel da Educação Matemática nessa cultura. Assim, os temas abordados nos inúmeros trabalhos desenvolvidos no grupo são vários: a formação de professores de Matemática; as narrativas; a História Oral; os manuais didáticos; instituições de vários níveis e modalidades de ensino nos quais atuam professores de Matemática e dos quais a Matemática faz parte; a História da Educação Matemática; a análise de livros antigos e contemporâneos (didáticos ou não); formação e conservação de acervos etc. Para maiores informações, consulte: 〈http://www2.fc.unesp.br/ghoem/index.php〉.
} 
quando atravessado pela presença de um grupo. Afinal, "9. Sabedoria pode ser que seja mais estudado em gente que em livros". A todos, muito obrigado!

\section{Referências}

ALBUQUERQUE JR., D. M. História: a arte de inventar o passado. Bauru: EDUSC, 2007.

BARROS, M. Poesia completa. São Paulo: Leya, 2010. [original 1998].

CLARETO, S. M. Espaço escolar e tornar-se o que se é: educabilidades e a constituição de novos modos de existir a partir do pensamento de Nietzsche. In: LOPES, J. J. M.; CLARETO, S. M. (Org.). Espaço e Educação: travessias e atravessamentos. Araraquara: Junqueira \& Marin, 2007. p. 43-56.

DELEUZE, G.; GUATTARI, F. Mil platôs: capitalismo e esquizofrenia. Tradução de Aurélio G. Neto e Célia P. Costa. São Paulo: Ed. 34, 1995 [original 1980].

DUQUE-ESTRADA, E. M. Devires autobiográficos: a atualidade da escrita de si. Rio de Janeiro: NAU/PUC-Rio, 2009.

GOMES, M. L. M. Escrita autobiográfica e história da educação matemática. Boletim de Educação Matemática, Rio Claro, SP, v. 26, n. 42A, p. 105-137, abr. 2012.

FOUCAULT, M. As palavras e as coisas: uma arqueologia das ciências humanas. 8. ed. Tradução de Salma T. Muchail. São Paulo: Martins Fontes, 1999a [original 1981].

FOUCAULT, M. História da sexualidade I: a vontade de saber. 13. ed. Tradução de Maria T. C.; Albuquerque e J. A.; Guilhon Albuquerque. Rio de Janeiro: Edições Graal, 1999b [original 1976].

LARROSA, J. Nietzsche \& a Educação. 2. ed. Belo Horizonte: Autêntica, 2005. (Coleção Pensadores \& Educação)

LARROSA, J. Ensaio, diário e poema como invariantes da autobiografia: a propósito de um "poema de formação" de Andrés Sánchez Robayna. In: SOUZA, E. C.; ABRAHÃO, M. H. M. B. Tempos, narrativas e ficções: a invenção de si. Porto Alegre: EDIPUCRS/EDUNEB, 2006. p. 183-202.

NIETZSCHE, F. Obras completas. São Paulo: Nova Cultural, 1999.

RAMOS DO Ó, J. Para uma crítica das artes da existência e da ideia de consciência na modernidade: a problematização foucaultiana. In: VICENTI, P. P.; ABRAHÃO, M. H. M. B. (Org.). Sentidos, potencialidades e usos da (auto)biografia. São Paulo: Cultura Acadêmica, 2010. p. $19-48$.

ROLNIK, S. Pensamento, corpo e devir: uma perspectiva ético/estético/política no trabalho acadêmico, 1993. Disponível em: <http://www.pucsp.br/nucleodesubjetividade/Textos/SUELY/pensamentocorpodevir.pdf $>$. Acesso em: 10 mar 2012.

ROOS, A. P. Nunca se sabe como alguém aprende... In: COLÓQUIO FRANCOBRASILEIRO DE FILOSOFIA DA EDUCAÇÃO, 2., 2004, Rio de Janeiro. Anais... Rio de Janeiro, UERJ, 2004. CD-ROM.

Submetido em Agosto de 2013. Aprovado em Janeiro de 2014. 